\title{
The role of the North Atlantic overturning and deep ocean for multi-decadal global-mean-temperature variability
}

\author{
C. F. Schleussner ${ }^{1,2}$, J. Runge ${ }^{1,3}$, J. Lehmann ${ }^{1,2}$, and A. Levermann ${ }^{1,2}$ \\ ${ }^{1}$ Potsdam Institute for Climate Impact Research, Telegrafenberg A62, 14473 Potsdam, Germany \\ ${ }^{2}$ Physics Institute, Potsdam University, Potsdam, Germany \\ ${ }^{3}$ Department of Physics, Humboldt University, Berlin, Germany \\ Correspondence to: C. F. Schleussner (schleussner@pik-potsdam.de)
}

Received: 7 August 2013 - Published in Earth Syst. Dynam. Discuss.: 6 September 2013

Revised: - Accepted: 11 August 2013 - Published: 20 February 2014

\begin{abstract}
Earth's climate exhibits internal modes of variability on various timescales. Here we investigate multi-decadal variability of the Atlantic meridional overturning circulation (AMOC), Northern Hemisphere sea-ice extent and global mean temperature (GMT) in an ensemble of CMIP5 models under control conditions. We report an inter-annual GMT variability of about $\pm 0.1^{\circ} \mathrm{C}$ originating solely from natural variability in the model ensemble. By decomposing the GMT variance into contributions of the AMOC and Northern Hemisphere sea-ice extent using a graph-theoretical statistical approach, we find the AMOC to contribute $8 \%$ to GMT variability in the ensemble mean. Our results highlight the importance of AMOC sea-ice feedbacks that explain $5 \%$ of the GMT variance, while the contribution solely related to the AMOC is found to be about $3 \%$. As a consequence of multi-decadal AMOC variability, we report substantial variations in North Atlantic deep-ocean heat content with trends of up to $0.7 \times 10^{22} \mathrm{~J} \mathrm{decade}^{-1}$ that are of the order of observed changes over the last decade and consistent with the reduced GMT warming trend over this period. Although these temperature anomalies are largely densitycompensated by salinity changes, we find a robust negative correlation between the AMOC and North Atlantic deepocean density with density lagging the AMOC by 5 to $11 \mathrm{yr}$ in most models. While this would in principle allow for a self-sustained oscillatory behavior of the coupled AMOCdeep-ocean system, our results are inconclusive about the role of this feedback in the model ensemble.
\end{abstract}

\section{Introduction}

Multi-decadal variability of the climate system has been studied intensively, with a special focus on the last millennium and climate variability on centennial timescales (e.g., Eby et al., 2013; Fernández-Donado et al., 2013; Ortega et al., 2011; Fidel et al., 2011; Otterå et al., 2010; Hofer et al., 2011). Among others, a dominant mode of global climate variability is the Atlantic multi-decadal oscillation (AMO) (Schlesinger and Ramankutty, 1994) in the North Atlantic that is evident in ocean records over the last $8000 \mathrm{yr}$ (Knudsen et al., 2011). The AMO as a signal of anomalous seasurface temperatures in the North Atlantic has been found to have profound influence on other climate phenomena such as the Atlantic hurricane frequency (Vimont and Kossin, 2007; Zhang and Delworth, 2009), West African monsoon and Sahel rainfall (Mohino et al., 2010).

Model studies suggest that the multi-decadal mode in North Atlantic sea-surface temperatures (SSTs) is closely related to variability of the Atlantic meridional overturning circulation (AMOC) (Timmermann and Latif, 1998; Knight et al., 2005; Delworth et al., 2007; Park and Latif, 2011; Ba et al., 2013) with models exhibiting AMOC variability on multi-decadal to multi-centennial timescales (Menary et al., 2011; Wouters et al., 2012). The origin of these multidecadal modes is not yet fully understood. Already simple box models are found to produce multi-decadal variability as a result of delayed advection (Griffies and Tziperman, 1995; Lee and Wang, 2010), and Dijkstra et al. (2006) report a multi-decadal mode in models of different complexity driven by horizontal temperature anomalies (Te Raa and Dijkstra, 2002; Sévellec and Fedorov, 2013). By analyzing 


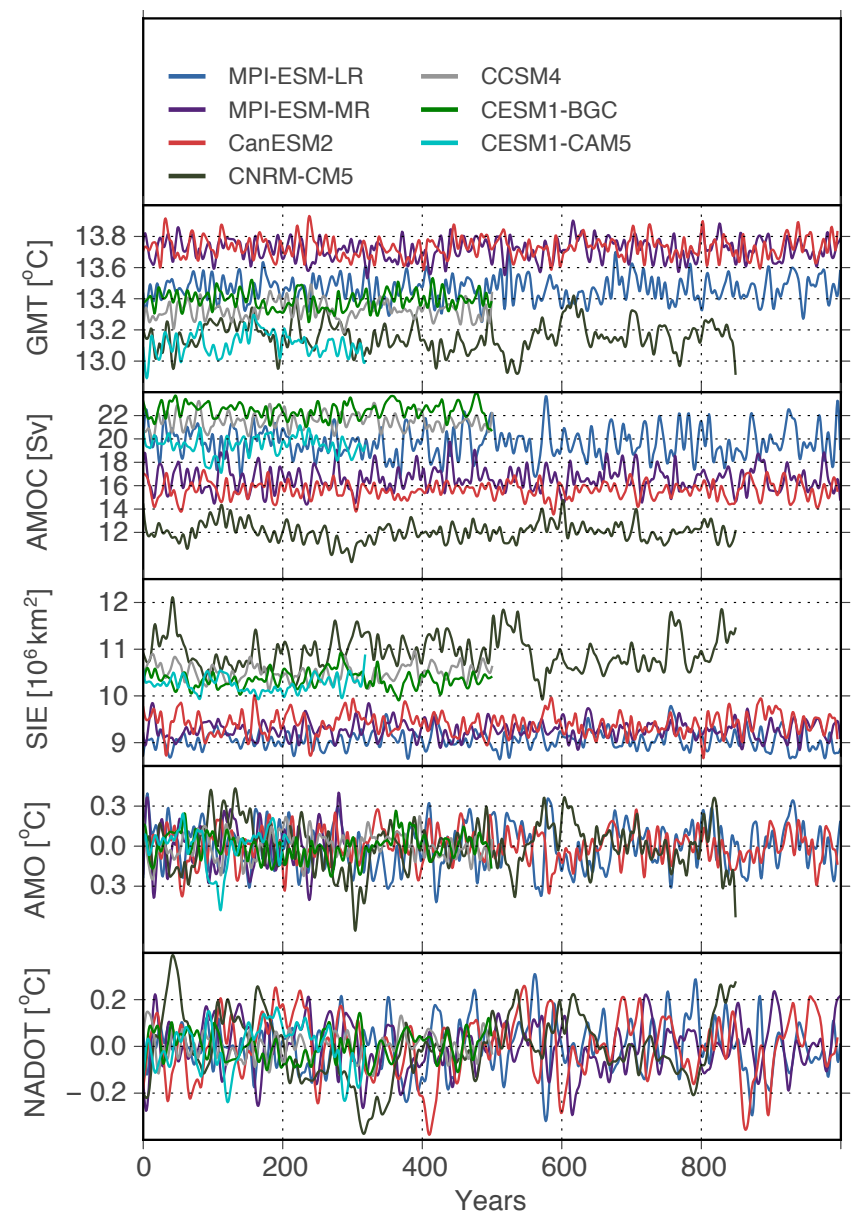

Fig. 1. Time series for GMT, AMOC, Northern Hemisphere seaice extent (SIE), the Atlantic multi-decadal oscillation (AMO) index and North Atlantic deep-ocean (NADO) temperature for seven CMIP5 models. A $10 \mathrm{yr}$ Butterworth low-pass filter is applied to the time series.

observational records, Dima and Lohmann (2010) find two distinct modes in observed Atlantic SST over the last century. Consistently, Park and Latif (2008) report multiple modes of AMOC variability in the Kiel Climate Model with a multi-centennial mode originating in the Southern Ocean and a multi-decadal one of Northern Hemisphere origin.

While several model studies find stochastic atmospheric forcing to be the dominant driver of the Northern Hemisphere variability component (Eden and Willebrand, 2001; Tulloch and Marshall, 2012), others report variations in Labrador Sea convection as a possible origin (Bentsen et al., 2004; Medhaug et al., 2011; Persechino et al., 2012). Delworth and Zeng (2012) and Ba et al. (2013) find salinity advection to drive variability in Labrador Sea convection, where salinity anomalies of subtropical and Arctic origin are found to play a role (Jungclaus et al., 2005). Born et al. (2012) identified this salinity advection feedback on subpolar convection as a potential driver of multi-stability of the horizon-
Table 1. List of CMIP5 models analyzed in this study.

\begin{tabular}{lc}
\hline Modeling center (or group) & Model name \\
\hline $\begin{array}{l}\text { Max Planck Institute } \\
\text { for Meteorology }\end{array}$ & $\begin{array}{c}\text { MPI-ESM-LR } \\
\text { MPI-ESM-MR }\end{array}$ \\
\hline $\begin{array}{l}\text { Canadian Centre for Climate } \\
\text { Modelling and Analysis }\end{array}$ & CanESM2 \\
\hline $\begin{array}{l}\text { Centre National de Recherches } \\
\text { Météorologiques }\end{array}$ & CNRM-CM5 \\
\hline $\begin{array}{l}\text { National Center for } \\
\text { Atmospheric Research }\end{array}$ & CCSM4 \\
\hline $\begin{array}{l}\text { Community Earth System } \\
\text { Model Contributors }\end{array}$ & CESM1-BGC \\
\hline
\end{tabular}

tal subpolar gyre circulation (Levermann and Born, 2007) in a multi-model study. The existence of such a multi-stability was found to greatly enhance subpolar variability close to the system's internal threshold (Mengel et al., 2012).

Atlantic variability is found to contribute significantly to Northern Hemisphere variations (Zhang et al., 2007; Knight et al., 2005, 2006) and eventually to global mean temperature (GMT). Zanchettin et al. (2010) find multi-decadal AMOC variations to be a major source of GMT variability over the last millennium, and Feulner et al. (2013) report meridional heat transport in the Atlantic to be the dominant process behind the persistent temperature difference between the Northern Hemisphere and Southern Hemisphere in an unperturbed climate. Results of a multi-model intercomparison suggest that multi-decadal variability in the high northern latitudes might be a major source of deviations within the CMIP5 model ensemble and in comparison with observational data over the 20th century (Jones et al., 2013). Besides oceanic contribution, sea-ice retreat has been a dominant contributor to observed northern high-latitude warming over the recent decades (Holland and Bitz, 2003; Screen and Simmonds, 2010).

Here, we first disentangle the contributions of AMOC and sea-ice variability to GMT variations in unperturbed control runs of the CMIP5 model ensemble using graph-theoretical statistical models (Runge et al., 2012a; Ebert-Uphoff and Deng, 2012, denoted graphical models hereafter) and commonality analysis (). We relate AMOC variability to North Atlantic deep-ocean temperature and salinity and investigate an internal advective feedback mechanism. The magnitude of the deep-ocean warming rate that is found in the CMIP5 models is consistent with the observed changes over the past decade. The link between GMT reduction and deep-ocean warming is quantitatively consistent with the past reduction in the GMT warming trend. 


\section{Temperature-circulation relations in the climate model ensemble CMIP5}

We analyze the unperturbed control run of seven atmosphere-ocean general circulation models (AOGCMs) from the Coupled Model Intercomparison Project Phase 5 CMIP5 (Taylor et al., 2012) - which provides all diagnostics required for our analysis and at minimum $300 \mathrm{yr}$ of model data (listed in Table 1). Figure 1 shows the annual time series for GMT, AMOC, AMO and Northern Hemisphere sea-ice extent (SIE) as well as North Atlantic deep ocean (NADO) temperature $\left(45^{\circ}\right.$ to $\left.65^{\circ} \mathrm{N}, z=1000-2000 \mathrm{~m}\right)$. The AMOC is derived as the vertical maximum of the stream function at $45^{\circ} \mathrm{N}$ and the AMO as the anomaly of Atlantic SSTs between $30^{\circ}$ and $65^{\circ} \mathrm{N}$. We find substantial inter-annual variations for all quantities investigated, notably a GMT variability of about $\pm 0.1{ }^{\circ} \mathrm{C}$ (standard deviation) and a AMOC variability of $\pm 1.1 \mathrm{~Sv}$ in the ensemble mean. Values for the individual models and the other quantities are given in Table 2. The corresponding power spectra are depicted in Fig. 2. We find two coherent modes in AMOC, GMT and SIE for the MPI-ESM-LR(-MR) model with around 30 and 40 (45) yr period, which are significant at the $95 \%$ level. The CanESM2 spectrum also exhibits significant AMOC modes at around 25 and $40 \mathrm{yr}$, whereas only the $25 \mathrm{yr}$ mode is present also in the GMT and SIE spectra, though not significant at the $95 \%$ level. A $25 \mathrm{yr}$ mode is also present in the CNRM-CM5 spectrum.

The time series of all other models are considerably shorter (500 yr or less), which reduces the signal to noise ratio and thus leads to less or no significant spectral peaks. Despite that, the AMOC spectrum for the CESM1-BGC exhibits significant AMOC modes at around 30 and $60 \mathrm{yr}$.

Cross-correlations between the AMOC and AMO, GMT and SIE reveal a clear relation between AMO and AMOC in all models with some models exhibiting an AMOC lead by several years (Fig. 3). We also find a robust positive correlation at zero or $1 \mathrm{yr}$ lag between AMOC and GMT significant at the $95 \%$ significance level as well as a negative peak between AMOC and SIE. The cross-correlation for the AMOC and GMT in CNRM-CM5 model is significant, but does not exhibit a clear peak as a consequence of a very weak AMOC mean state and weak variability on less than centennial timescales in this model (compare Fig. 1).

Significant cross-correlation does not, however, imply physical relevance. To test for the importance of the high northern latitudes for absolute GMT variability, we derived the latitude-dependent contribution of surface air temperature (SAT) anomalies to the GMT signal. Figure 4 depicts the explained variance $\left(R^{2}\right)$ of the GMT time series by the zonal and meridional integrated SAT anomalies north of the latitude drawn on the $x$ axis. The expected surface area contribution by latitude, assuming SAT anomalies to be uniform across the globe, is drawn for comparison (in grey). We find about one third of the GMT variance to originate

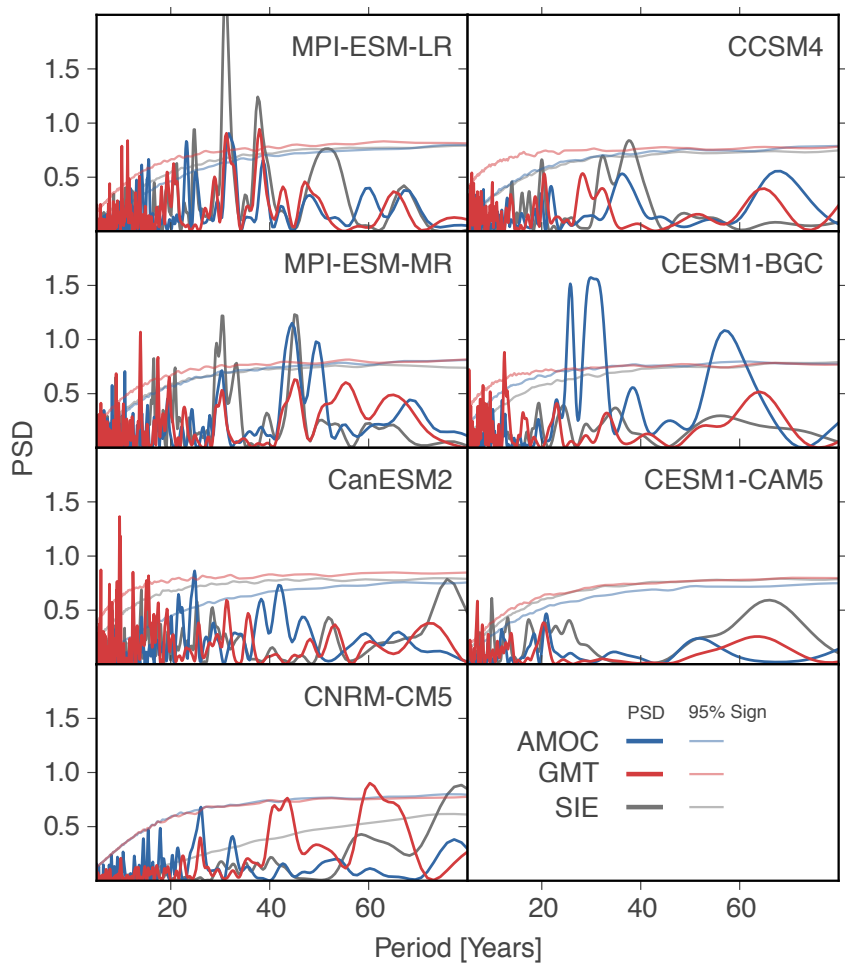

Fig. 2. Power spectral density of AMOC (blue), GMT (red) and SIE (grey). Light lines indicate the $95 \%$ significance levels determined by a $N=10000$ ensemble of a red noise first order auto-regressive process fitted to each of the quantities. In this plot, all amplitudes are rescaled relative to the corresponding maximum of the $95 \%$ significance level.

north of $45^{\circ} \mathrm{N}$ in the ensemble mean exceeding their share expected purely by the surface area. We applied a forwardbackward Butterworth low-pass filter with cutoff frequencies from 10 to $50 \mathrm{yr}$ to our time series and find the northern latitude contribution to increase with increased filtering in all models except the CCSM4 and CNRM-CM5. Half of the multi-decadal GMT variance in the MPI-ESM-LR originates north of $45^{\circ} \mathrm{N}$, and we hypothesize AMOC and SIE as likely drivers. The CCSM4 actually shows a decrease for multi-decadal variability, but our analysis suggests the high latitudes of the Southern Hemisphere to be dominant contributors to GMT variability in this model (compare Fig. 4). Thus, our results indicate that the high northern latitudes are indeed an important contributor to GMT variability on annual timescales and that this share increases for multidecadal variability. We performed the same analysis with an ensemble of 30 CMIP5 models (not shown) confirming our results. 
Table 2. Inter-annual variability (standard deviation) of GMT, AMOC, Northern Hemisphere sea-ice extent (SIE), AMO and North Atlantic deep ocean temperature (NADOT). SAT $>45^{\circ} \mathrm{N}$ denotes the explained GMT variance integrated over the Northern Hemisphere north of $45^{\circ} \mathrm{N}$ as in Fig. 3. OHC SD: standard deviation of the North Atlantic deep ocean (NADO) $\left(45^{\circ}\right.$ to $\left.65^{\circ} \mathrm{N}, z=1000-2000 \mathrm{~m}\right)$ heat content (OHC). OHC rate: maximum decadal trend over the full time series.

\begin{tabular}{lcccccccc}
\hline & $\begin{array}{c}\text { GMT } \\
{\left[{ }^{\circ} \mathrm{C}\right]}\end{array}$ & $\begin{array}{c}\text { AMOC } \\
{[\mathrm{Sv}]}\end{array}$ & $\begin{array}{c}\text { SIE } \\
{\left[10^{6} \mathrm{~km}^{2}\right]}\end{array}$ & $\begin{array}{c}\text { AMO } \\
{\left[{ }^{\circ} \mathrm{C}\right]}\end{array}$ & $\begin{array}{c}\text { NADOT } \\
{\left[{ }^{\circ} \mathrm{C}\right]}\end{array}$ & $\begin{array}{c}\text { SAT }> \\
45^{\circ} \mathrm{N}\end{array}$ & $\begin{array}{c}\text { OHC SD } \\
{\left[10^{22} \mathrm{~J}\right]}\end{array}$ & $\begin{array}{c}\text { OHC RATE } \\
{\left[10^{22} \mathrm{Jdec}^{-1}\right]}\end{array}$ \\
\hline MPI-ESM-LR & 0.12 & 1.60 & 0.24 & 0.20 & 0.11 & 0.27 & 0.20 & 1.1 \\
MPI-ESM-MR & 0.10 & 1.35 & 0.24 & 0.20 & 0.10 & 0.27 & 0.21 & 1.0 \\
CanESM2 & 0.12 & 0.86 & 0.33 & 0.16 & 0.13 & 0.33 & 0.23 & 0.6 \\
CNRM-CM5 & 0.11 & 0.99 & 0.40 & 0.21 & 0.14 & 0.33 & 0.31 & 0.5 \\
CCSM4 & 0.10 & 0.87 & 0.22 & 0.13 & 0.06 & 0.36 & 0.16 & 0.5 \\
CESM1-BGC & 0.10 & 0.93 & 0.22 & 0.13 & 0.06 & 0.39 & 0.20 & 0.5 \\
CESM1-CAM5 & 0.11 & 1.00 & 0.21 & 0.17 & 0.10 & 0.39 & 0.22 & 0.7 \\
\hline Mean & 0.11 & 1.09 & 0.27 & 0.17 & 0.10 & 0.33 & 0.22 & 0.7 \\
\hline
\end{tabular}

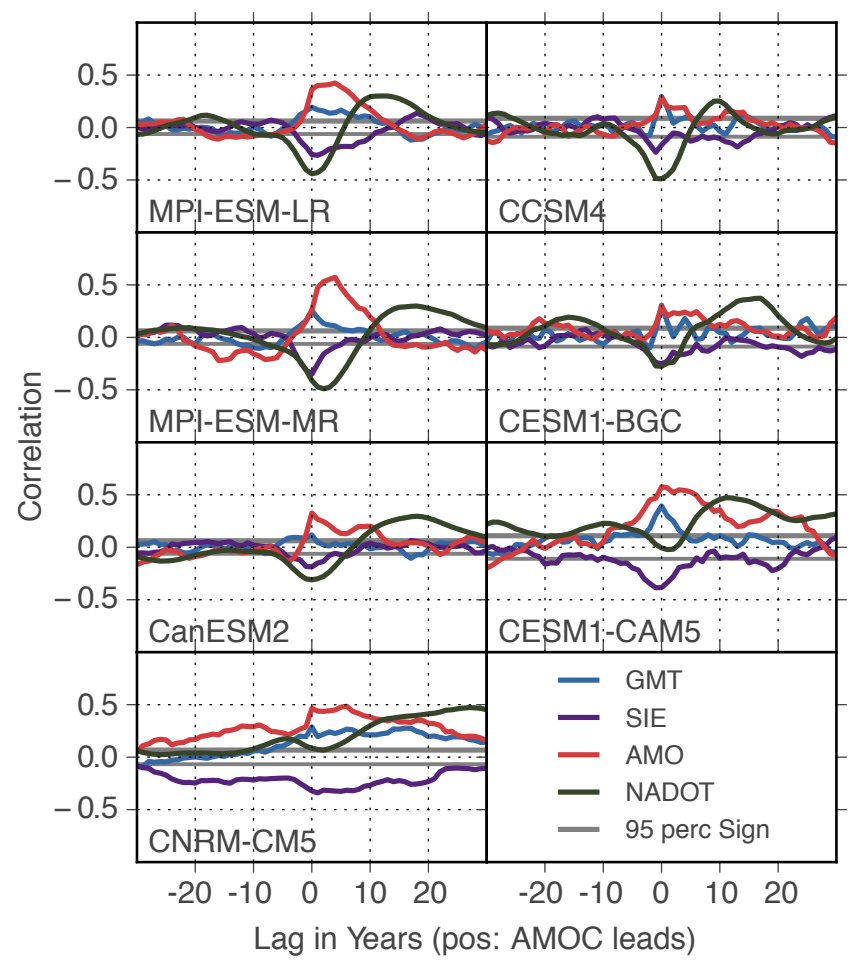

Fig. 3. Cross-correlations between AMOC and GMT, SIE, NADO temperature and the AMO index (positive: AMOC leads). The grey lines mark the two-tailed $95 \%$ significance range.

\section{Quantifying AMOC contributions to GMT variance}

Cross correlations need to be interpreted cautiously, since they are subject to several limitations. In the presence of strong auto-correlation, peaks in the cross-correlation can be amplified and shifted to larger time lags, limiting the interpretability of time delays in such systems (Runge et al., 2014). Additionally, in the global climate system with its complex coupled dynamic, also common driver effects and indirect chains can occur. A notional process $Z$ that drives two processes $X$ and $Y$ is called a common driver of $X$ and $Y$, whereas an indirect chain is present if process $X$ drives $Z$ and $Z$ drives $Y$, without a direct relation between $X$ and $Y$. In both cases, a non-zero cross-correlation between $X$ and $Y$ would be detected, even though no direct interaction is present.

\subsection{Graphical model analysis}

To overcome these limitations, graphical models can be used to identify causal relations in complex coupled systems (Ebert-Uphoff and Deng, 2012). Here we apply a graphical model approach introduced by Runge et al. (2012a, b). While this approach is also applicable to nonlinear interactions, here the linear case as discussed in Runge et al. (2014) is used to determine linear causal interdependencies. In the following, we illustrate the concept with a simple example and refer to the references for further details on the methodology.

Consider the simple bivariate first-order auto-regressive stochastic process $(\mathrm{AR}(1))$ :

$$
\begin{aligned}
X_{t} & =a X_{t-1}+\epsilon_{t}^{\mathrm{X}} \\
Y_{t} & =c X_{t-1}+b Y_{t-1}+\epsilon_{t}^{\mathrm{Y}},
\end{aligned}
$$

where $X$ and $Y$ denote the two variables of the stochastic process with $a, b$ and $c$ as constant coefficients. The coefficients $a$ and $b$ represent the auto-regressive contribution of $X$ and 


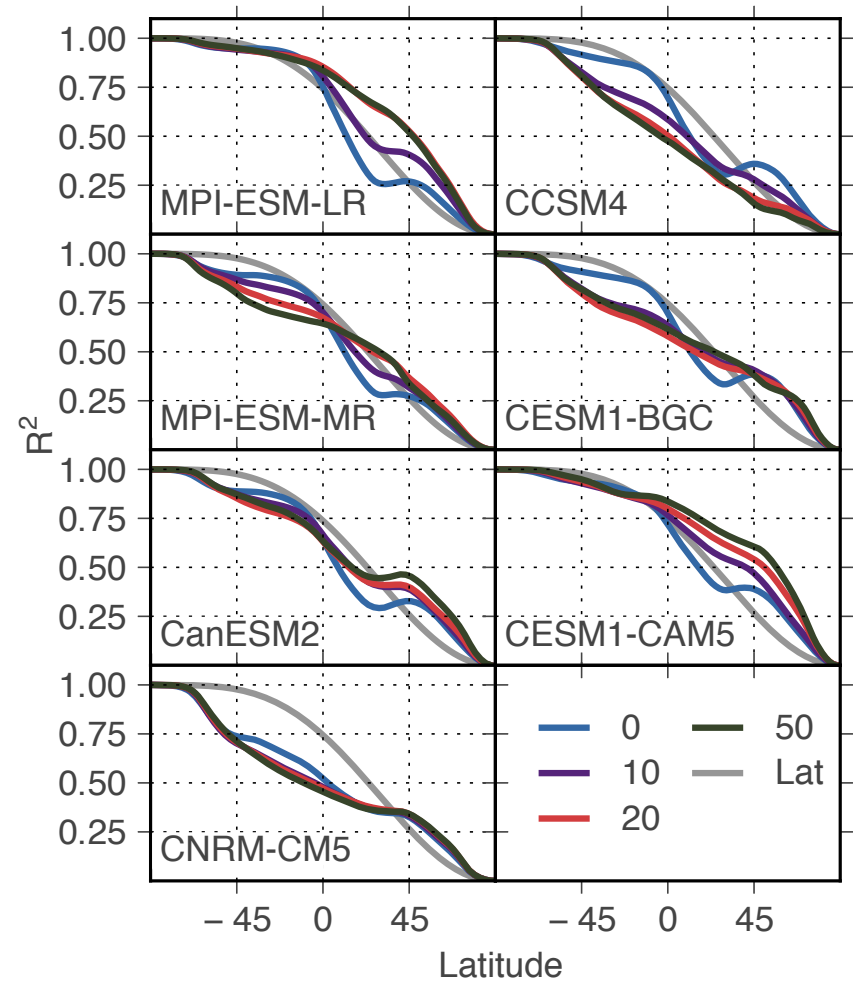

Fig. 4. Meridional dependence of the GMT variance. The horizontally averaged yearly SAT anomalies are integrated from $90^{\circ} \mathrm{N}$ southward. The value for a given latitude marks the explained variance $\left(R^{2}\right)$ of the GMT time series by the integrated SAT variance north of it. Colors indicate different low-pass filters applied. The grey line marks the variance contribution assuming equally distributed GMT variance. The explained variances of the unfiltered GMT signal that originates from north of $45^{\circ} \mathrm{N}$ are listed in Table 2 .

$Y$ respectively, and $|a|,|b|<1$ is required for the process to be stationary. $c$ gives the coupling between the two and can in principle attain any finite value. $\epsilon_{t}^{\mathrm{X}}$ and $\epsilon_{t}^{\mathrm{Y}}$ are independent, identically distributed Gaussian random variables with a given covariance matrix,

$\boldsymbol{\Sigma}=\left(\begin{array}{cc}\sigma_{X}^{2} & \sigma_{X Y} \\ \sigma_{X Y} & \sigma_{Y}^{2}\end{array}\right)$

and zero mean.

A time-series graph for this model can be constructed, where the nodes are represented by the time-dependent states $X_{t}, Y_{t}, X_{t-1}, Y_{t-1},(\ldots)$. Directed links (symbolized by $\rightarrow$ ) are given by non-zero coefficients $a, b, c$, and undirected contemporaneous links are given by non-zero entries in the inverse covariance matrix $\boldsymbol{\Sigma}$. This time-series graph for our model system is illustrated in Fig. 5. Note that time-series stationarity as a prerequisite for such an analysis implies that if " $X_{t-\tau} \rightarrow Y_{t}$ ", " $X_{t^{\prime}-\tau} \rightarrow Y_{t}$ '" is true for any $t^{\prime}$.

In real world systems, however, the exact relations between the investigated processes are often unknown, and

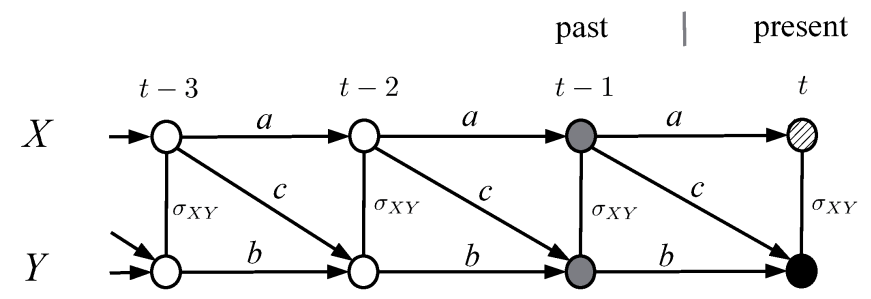

Fig. 5. Representation of the time-series graph of the simple coupled bivariate process $\left(X_{t}, Y_{t}\right)$ in Eq. (1) with the constant coefficients $a, b$ and $c . \sigma_{X Y}$ is the non-diagonal element of the covariance matrix. Process $Y_{t}$ (black node) is driven by $Y_{t-1}$ and $X_{t-1}$ (in grey) and has a contemporaneous link to $X_{t}$ (hatched). Due to stationarity, the same causal relation holds for all $t$.

a time-series graph algorithm as introduced in Runge et al. (2012b) can help to identify causalities in such complex coupled systems. As an illustration, consider the estimation of the parents of $Y$ in the time-series graph shown in Fig. 5. The algorithm tests possible links from all processes (including $Y$ ) at all lags up to a maximum delay (which can be specified accordingly; for the analysis presented below we use a maximum time lag of $30 \mathrm{yr}$ ). Here the hypothetical link " $X_{t-2} \rightarrow Y_{t}$ " would be tested by first checking whether the unconditional cross-correlation $\rho\left(X_{t-2} ; Y_{t}\right)$ is nonzero. Since there exists a path between $X_{t-2}$ and $Y_{t}$, this will be the case. In the next iteration step, the conditional linear dependence is tested. As a heuristic criterion for selecting the conditions in each test, we choose the conditions sorted by their correlation value in the previous step. Assuming $\rho\left(Y_{t-1} ; Y_{t}\right)>\rho\left(X_{t-1} ; Y_{t}\right)>\ldots$ in our example, the partial correlation $\rho\left(X_{t-2} ; Y_{t} \mid Y_{t-1}\right)$ that excludes the influence of $Y_{t-1}$ would be tested. This partial correlation would also be non-zero due to the unblocked path " $X_{t-2} \rightarrow X_{t-1} \rightarrow Y_{t}$ ". Also the test with the next-largest condition on $X_{t-1}$ yields a non-zero partial correlation. After some more tests with weaker conditions, the partial correlation $\rho\left(X_{t-2} ; Y_{t} \mid Y_{t-1}, X_{t-1}\right)$ would be found to vanish, such that the hypothetical link can be removed. An analogue procedure is applied for contemporaneous links, where all directed links are identified and iteratively more and more contemporaneous links are conditioned out (Runge et al., 2012b).

Following this procedure, we now construct a time-series graph for GMT, AMOC and SIE with a two-sided significance level of $99 \%$ for the partial correlation test. The resulting cross-links between AMOC, GMT and SIE are illustrated in Fig. 6. Across the whole ensemble, we robustly find contemporaneous links with a positive partial correlation between AMOC and GMT and a negative partial correlation between SIE and GMT. Several models also show negative "GMT $\rightarrow$ SIE" and "SIE $\rightarrow$ GMT" links at a time lag of 1 yr. On the one hand sea-ice reduction will lead to atmospheric warming (Holland and Bitz, 2003; Screen and Simmonds, 

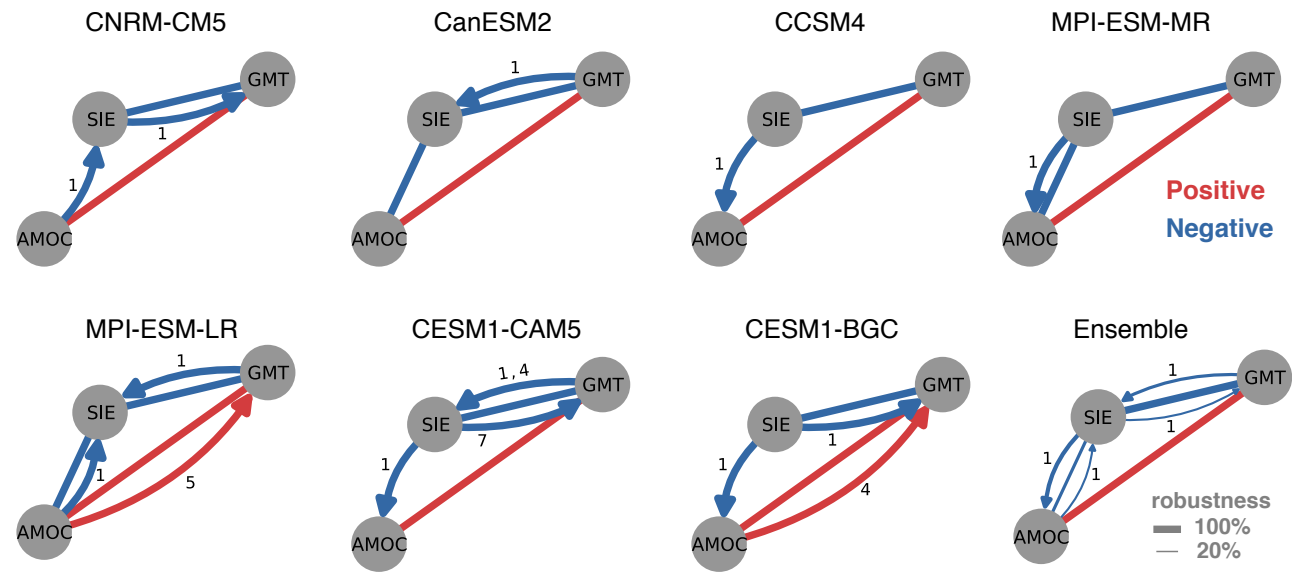

Fig. 6. Resulting time-series graphs for AMOC, GMT and SIE by applying a method introduced in Runge et al. (2012b). Based on the sign of the partial correlation as a result of the graph estimation algorithm, we denote positive (negative) partial correlations in red (blue). Direct links are indicated by curved lines with the associated time lags. Straight lines represent contemporaneous links at lag zero.

2010), but a warming anomaly could also cause additional sea-ice melt in particular during the summer and early autumn season. Thus, influences in both directions are present that could explain the model dependent presence of the lag-1 links.

The relation between AMOC and SIE differs substantially between the models, exhibiting links at zero lag as well as "AMOC $\rightarrow$ SIE" and "SIE $\rightarrow$ AMOC" links at time lag 1. A stronger AMOC leads to increased northward heat transport and thus to SIE reduction in the North Atlantic, which could explain the AMOC-SIE links. Levermann et al. (2007) identified increased oceanic heat loss as a result of reduced SIE in the North Atlantic to be a positive feedback on AMOC strength in a CMIP3 model ensemble, implying driving mechanisms that work both ways. Our results indicate that the strength of this individual processes differs substantially between the models investigated. Direct coupling between AMOC and SIE is located in the subpolar and polar Atlantic, while SIE comprises the sea-ice extent over the full Northern Hemisphere. Thus, an AMOC imprint might be present, but not significant in the compound SIE signal. To account for this, we performed the same analysis for SIE limited to the North Atlantic region and found similar results.

\subsection{Commonality analysis}

We use commonality analysis () to disentangle AMOC and SIE contributions to GMT variability. Commonality analysis allows a distinction of the explained variance by a multivariate system into unique components that are explained by the individual variables alone and common components that give the explained variance by the coupling between them.

As depicted in Fig. 6, the contemporaneous positive AMOC-GMT and negative SIE-GMT links are robust across all models in the ensemble. Therefore, we limit the decomposition of the GMT variability to the AMOC and SIE contribution at lag zero. Following, the unique contribution of AMOC to GMT variability $U_{\mathrm{AMOC}}$ derives as

$U_{\mathrm{AMOC}}=R_{\mathrm{FULL}}^{2}-R_{\mathrm{SIE}}^{2}$,

where $R_{\mathrm{FULL}}^{2}$ is the coefficient of determination (giving the explained variance) for the multivariate regression of the GMT on AMOC and SIE at lag zero. $R_{\mathrm{SIE}}^{2}$ is the explained variance of the univariate regression of GMT on SIE at lag zero. The unique SIE contribution $U_{\text {SIE }}$ can be derived accordingly.

The common contribution $C$ is given by the difference between $R_{\text {FULL }}^{2}$ and the sum of the unique contributions. All time series have been standardized (time series mean subtracted and divided by the standard deviation). In the ensemble average, we find a unique AMOC contribution of $3 \%$, SIE $14 \%$ and a common component of $5 \%$. In total, the coupled AMOC-SIE system contributes about $21 \%$ to GMT variance (see Table 3 for the coefficients of the individual models). We performed the same analysis for low-passfiltered time series and found a decrease in the AMOC unique contribution to $1 \%$, while the SIE and the common component increase to 21 and $9 \%$ respectively, in total explaining $31 \%$ of GMT variability.

We would like to emphasize that the analysis presented here is not a comprehensive study of Northern Hemisphere climate variability, since important sources of variability such as multi-decadal variability in the Pacific (Mantua et al., 1997) as well as continental variability are not included. Also interrelations between modes of atmospheric variability such as the North Atlantic and the Arctic oscillation (Hurrell and Deser, 2009) and AMOC as well as SIE, which have been studied intensively and shown to have substantial influence on North Atlantic climate variability (e.g., Tulloch and Marshall, 2012; Frankcombe et al., 2009; Medhaug et al., 2011), are not resolved. However, we find that SIE and AMOC 
Table 3. Results of the commonality analysis of GMT variability and the AMOC and SIE contribution at lag zero. $U_{\mathrm{AMOC}}$ and $U_{\mathrm{SIE}}$ denote the unique AMOC and SIE contribution and $\mathrm{C}$ the common component. $R_{\mathrm{FULL}}^{2}$ gives the explained GMT variance by the coupled system.

\begin{tabular}{lcccc}
\hline & $U_{\text {AMOC }}$ & $U_{\text {SIE }}$ & $\mathrm{C}$ & $R_{\text {FULL }}^{2}$ \\
\hline MPI-ESM-LR & 0.01 & 0.13 & 0.03 & 0.16 \\
MPI-ESM-MR & 0.02 & 0.09 & 0.05 & 0.16 \\
CanESM2 & $<0.01$ & 0.20 & 0.01 & 0.21 \\
CNRM-CM5 & 0.02 & 0.18 & 0.06 & 0.26 \\
CCSM4 & 0.06 & 0.08 & 0.03 & 0.17 \\
CESM1-BGC & 0.06 & 0.07 & 0.05 & 0.19 \\
CESM1-CAM5 & 0.02 & 0.22 & 0.08 & 0.32 \\
\hline Mean & 0.03 & 0.14 & 0.05 & 0.21 \\
\hline
\end{tabular}

variability already contributes about two thirds to the $33 \%$ explained GMT variance that is found to originate from north of $45^{\circ} \mathrm{N}$.

\section{Deep ocean heat uptake and density}

As shown in the previous section, a significant part of multidecadal GMT variability is due to changes in the North Atlantic. But when investigating oceanic contributions to GMT variability, direct surface feedbacks as well as oceanic heat uptake variability have to be considered (Levitus et al., 2000; Meehl et al., 2011; Balmaseda et al., 2013). As shown in Fig. 1, we find substantial variations in North Atlantic deep-ocean (NADO) temperatures $\left(45^{\circ}\right.$ to $65^{\circ} \mathrm{N}, z=1000$ $2000 \mathrm{~m})$. NADO heat content variability ranges from a standard deviation of $0.16 \times 10^{22} \mathrm{~J}$ for the CCSM4 to $0.31 \times 10^{22} \mathrm{~J}$ for the CNRM-CM5 model with an ensemble mean of $0.22 \times$ $10^{22} \mathrm{~J}$. Numbers for the individual models are given in Table 4. Our results compare well with Mauritzen et al. (2012), who find a peak-to-peak variability of about $1 \times 10^{22} \mathrm{~J}$ for the entire extratropical North Atlantic deep ocean (700-2000 m) between $20^{\circ}$ and $65^{\circ} \mathrm{N}$.

Such anomalies in heat content will also lead to substantial variations in NADO density as depicted in Fig. 7 (red curve). However, density variations caused by temperature change are largely compensated by salinity changes (in blue, inverted) leading to a weaker overall density signal (in black) in line with observational studies (Curry et al., 1998; Yashayaev et al., 2007). Figure 8 depicts the strength of the density compensation, and we find substantial variance between the model ensemble (slope of -1 indicates full compensation), ranging from full or even slight overcompensation for the CNRM-CM5 and the CESM1-CAM5 model to only partial compensation in the CCSM4 and the MPI-ESMLR. Apart from the CNRM-CM5 and the CESM1-CAM5 model, all models show substantial deviation from full compensation (which are significant at one standard deviation except for the CanESM2), indicating a systematic process behind the phenomenon. As shown in Fig. 9, we find deepocean density changes to be related to the AMOC in our model ensemble. Except for the CNRM-CM5 model that has a very weak AMOC and exhibits no significant multidecadal modes of AMOC variability as discussed above, all models show a positive correlation between the AMOC and the NADO thermal density component at zero lag and a significant anti-correlation with a time lag between 10 and $20 \mathrm{yr}$. Cross-correlations between AMOC and NADO salinity at lag zero are generally weaker over the model ensemble with only the MPI-ESM-LR and MPI-ESM-MR as well as the CanESM2 model exhibiting a significant negative peak. Still, most models show a positive correlation at multidecadal timescales. Taken together, these results indicate that a strong AMOC leads to a NADO warming and salinification on multi-decadal timescales. In the combined density signal, however, only the MPI-ESM-LR model shows a significant AMOC NADO density peak between lag 10 and 20, while a robust correlation at zero lag is found for most models in the ensemble.

Again we performed a time-series graph analysis as in Sect. 3.1 to account for the autocorrelations in both time series. Our analysis yields a positive contemporaneous AMOC NADO density link and directed negative AMOC $\rightarrow$ NADO density links with 5 to $11 \mathrm{yr}$ time lag that are significant at the $99 \%$ level for all models except the CNRM-CM5 (not shown). The robust zero lag link between AMOC and NADO density suggests a causal relation. A linear relationship between meridional density differences and AMOC strength is assumed in conceptual approaches (Stommel, 1961; Rahmstorf, 1996; Johnson et al., 2007; Marzeion and Drange, 2006; Fürst and Levermann, 2012; Cimatoribus et al., 2012) and confirmed by a variety of studies with models of different levels of complexity (e.g., Manabe and Stouffer, 1988; Thorpe et al., 2001; Griesel and Maqueda, 2006; Dijkstra, 2008; Huisman et al., 2010). The physical mechanism behind this relationship is controversial in a predominantly geostrophic ocean, although a number of explanations for this relation have been proposed (Marotzke, 1997; Gnanadesikan, 1999; Schewe and Levermann, 2009; Sijp et al., 2012). Gregory and Tailleux (2011) present a kinetic energy analysis of the AMOC, finding the pressure gradient force to be a dominant driver of the AMOC in the high northern latitudes by conversion of potential to kinetic energy. They report good correlation between changes in the North Atlantic pressure gradient force and the AMOC under $\mathrm{CO}_{2}$-forced climate change on decadal timescales (their Fig. 10) and find changes in the pressure gradient force to be dominated by buoyancy changes in the northern North Atlantic, which is confirmed by Saenko (2013) for the CanESM2 model. Consequently, they propose a linear relation $\Delta M \propto \Delta \rho$ in the North Atlantic. Such a scaling is also supported by an analytical study by Sijp et al. (2012). Thus, Gregory and Tailleux (2011) provide a physical mechanism for the zero-lag link between 
Table 4. Results of the multivariate regression of the conceptual coupled AMOC-NADO density system as in Eq. (4) to the individual models.

\begin{tabular}{lcccccccccc}
\hline & $a_{\rho}$ & $c_{M \rho}$ & $a_{M}$ & $c_{\rho M}$ & $\sigma_{\rho}^{2}$ & $\sigma_{M}^{2}$ & $\sigma_{M \rho}$ & $\tau$ & $R_{M}^{2}$ & $R_{\rho}^{2}$ \\
\hline MPI-ESM-LR & $0.98 \pm 0.01$ & $-0.08 \pm 0.01$ & $0.61 \pm 0.03$ & $0.18 \pm 0.03$ & 0.07 & 0.48 & 0.04 & 7.0 & 0.52 & 0.93 \\
MPI-ESM-MR & $0.99 \pm 0.01$ & $-0.06 \pm 0.01$ & $0.57 \pm 0.03$ & $0.13 \pm 0.03$ & 0.05 & 0.59 & 0.07 & 8.0 & 0.40 & 0.95 \\
CanESM2 & $1.01 \pm 0.01$ & $-0.07 \pm 0.01$ & $0.64 \pm 0.03$ & $0.13 \pm 0.03$ & 0.03 & 0.49 & 0.03 & 6.0 & 0.51 & 0.97 \\
CCSM4 & $1.01 \pm 0.01$ & $-0.11 \pm 0.01$ & $0.37 \pm 0.04$ & $0.38 \pm 0.04$ & 0.07 & 0.56 & 0.05 & 5.0 & 0.45 & 0.93 \\
CESM1-BGC & $0.97 \pm 0.01$ & $-0.05 \pm 0.01$ & $0.3 \pm 0.04$ & $0.39 \pm 0.04$ & 0.08 & 0.64 & 0.05 & 11.0 & 0.36 & 0.92 \\
CESM1-CAM5 & $1.02 \pm 0.01$ & $-0.07 \pm 0.01$ & $0.49 \pm 0.05$ & $0.24 \pm 0.05$ & 0.03 & 0.56 & 0.04 & 6.0 & 0.45 & 0.97 \\
\hline Mean & 1.0 & -0.07 & 0.5 & 0.24 & 0.05 & 0.55 & 0.05 & 7.2 & 0.45 & 0.95 \\
\hline
\end{tabular}

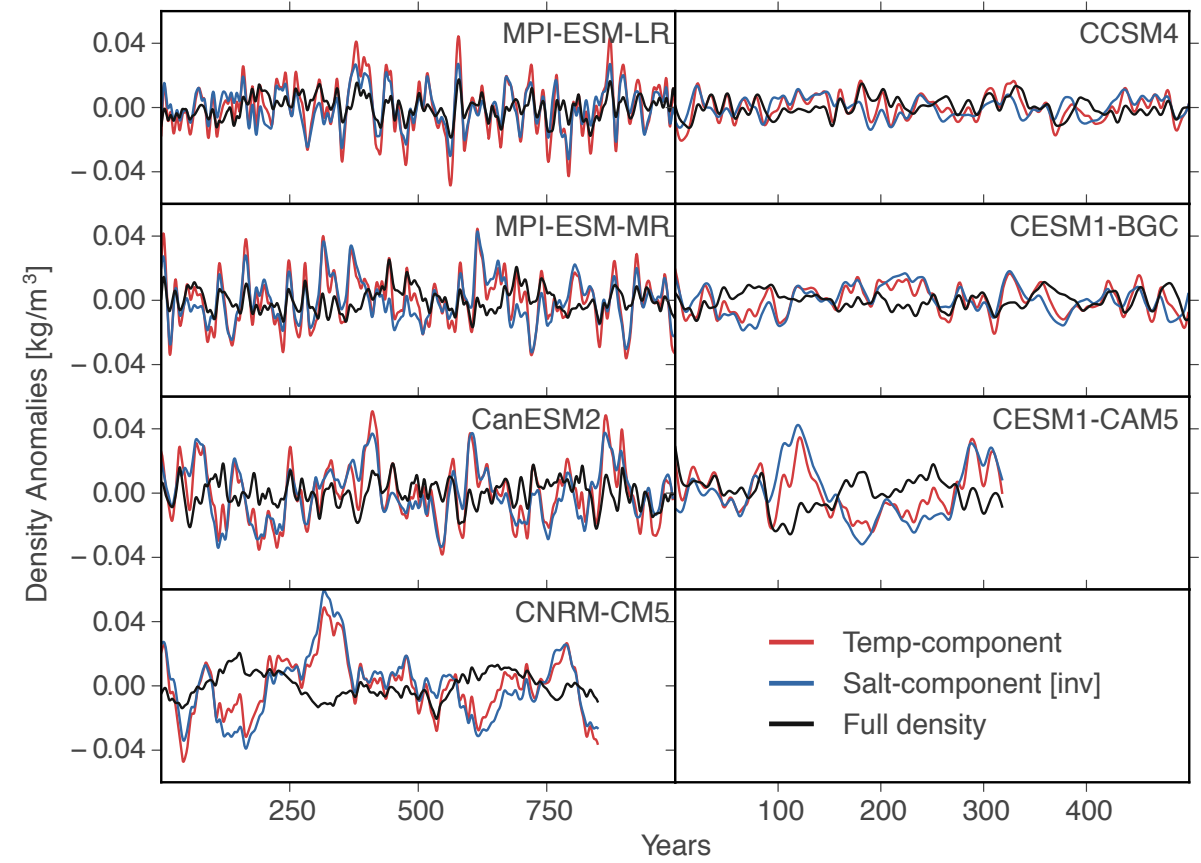

Fig. 7. North Atlantic deep ocean density time series (black) and its salinity-related (blue, inverted) and temperature-related (red) components.

NADO and AMOC that is found in all models in the ensemble. Additionally, also a direct feedback between AMOC and NADO temperature and salinity via subpolar convection might play a role. Increased sea surface salinity as a consequence of a strengthened AMOC could lead to enhanced subpolar convection (Mengel et al., 2012) and as a consequence to a deep-ocean freshening and cooling (Yashayaev, 2007).

Based on our findings, we study a conceptual bivariate statistical model for the change in NADO density $\Delta \rho$ and the AMOC change $\Delta M$ :

$$
\begin{aligned}
\Delta \rho_{t} & =a_{\rho} \Delta \rho_{t-1}+c_{M \rho} \Delta M_{t-\tau}+\epsilon_{t}^{\rho} \\
\Delta M_{t} & =a_{M} \Delta M_{t-1}+c_{\rho M} \Delta \rho_{t}+\epsilon_{t}^{M},
\end{aligned}
$$

with $a_{\rho}$ and $a_{M}$ denoting the auto-regressive coefficients and $c_{\rho M}$ and $c_{M \rho}$ the coupling coefficients for $\Delta \rho \rightarrow \Delta M$ at lag zero and $\Delta M \rightarrow \Delta \rho$ with a time lag $\tau$. Results of the fit to the model ensemble time series are given in Table 4 . In the ensemble mean, we find about $95 \%$ of the density and about $45 \%$ of the AMOC variance explained by this simple conceptual model, although these good fitting results are partly due to the very strong auto-correlation in the system.

Equation (4) can be written as an auto-regressive system, for which power spectra can be derived analytically (Brockwell and Davis, 2009). Figure 10 depicts analytical spectra for the conceptual model (FULL, green) in comparison with a system without the AMOC-NADO density link (e.g., because of complete density compensation by salinity; $c_{M \rho}=$ 0 , in blue) and an AR(1) process fitted to the AMOC time series (grey). Note that the $c_{M \rho}=0$ and $\mathrm{AR}(1)$ coefficients may differ from the fully coupled system given in Table 4 . We find an enhancement of multi-decadal variability for FULL vs. $c_{M \rho}=0$ in all models, but only for the MPI-ESM-LR, the CCSM4 and the CESM1-BGC, it also exceeds the spectral density of the fitted $\operatorname{AR}(1)$ process for periods between 


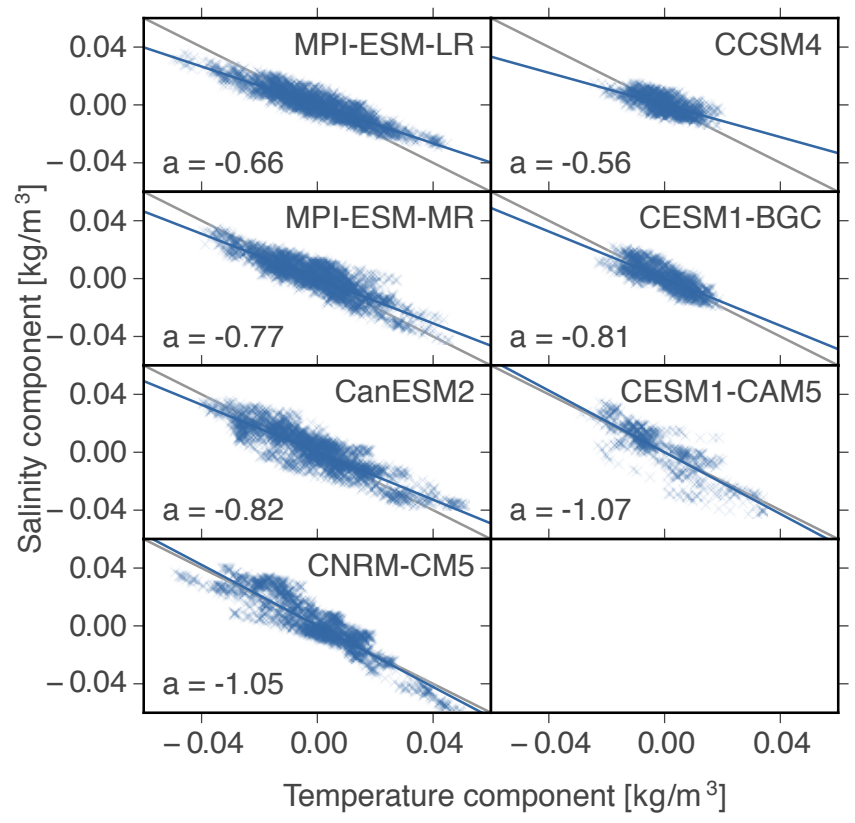

Fig. 8. Relation of temperature- and salinity-driven NADO density changes. The blue line marks the linear fit with slope $a$. The $a=-1$ line is drawn in grey.

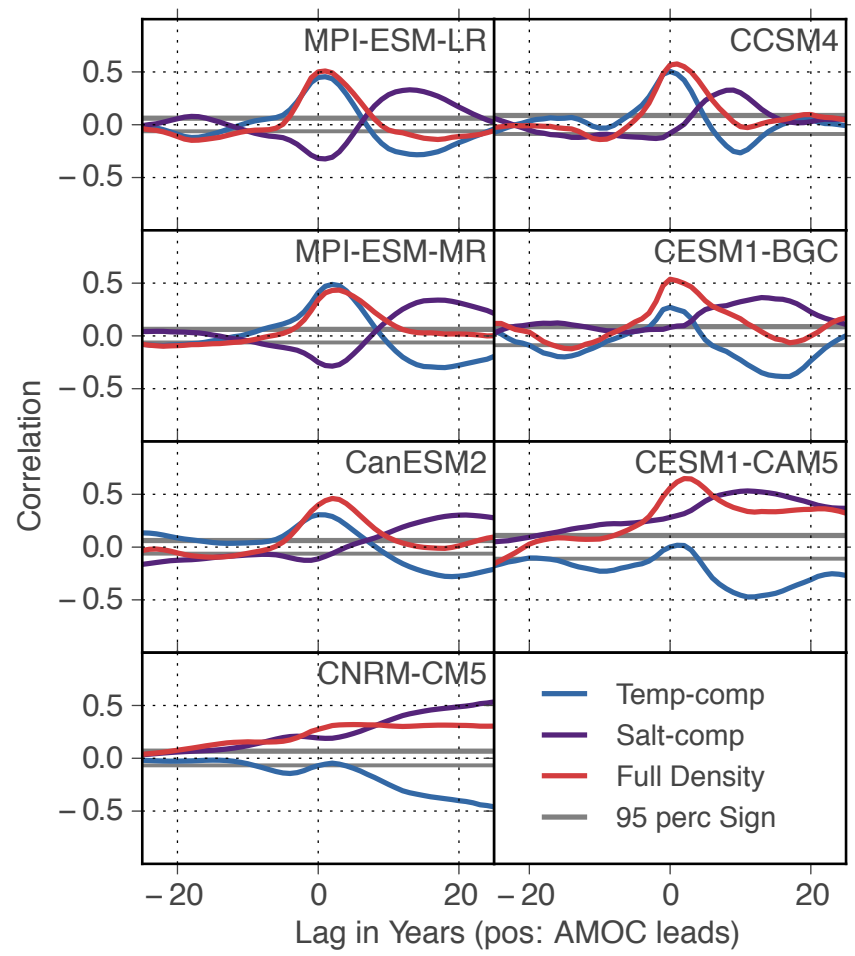

Fig. 9. Cross-correlations between AMOC and NADO density and its temperature- and salinity-related components (positive: AMOC leads). The grey lines mark the two-tailed $95 \%$ significance range.

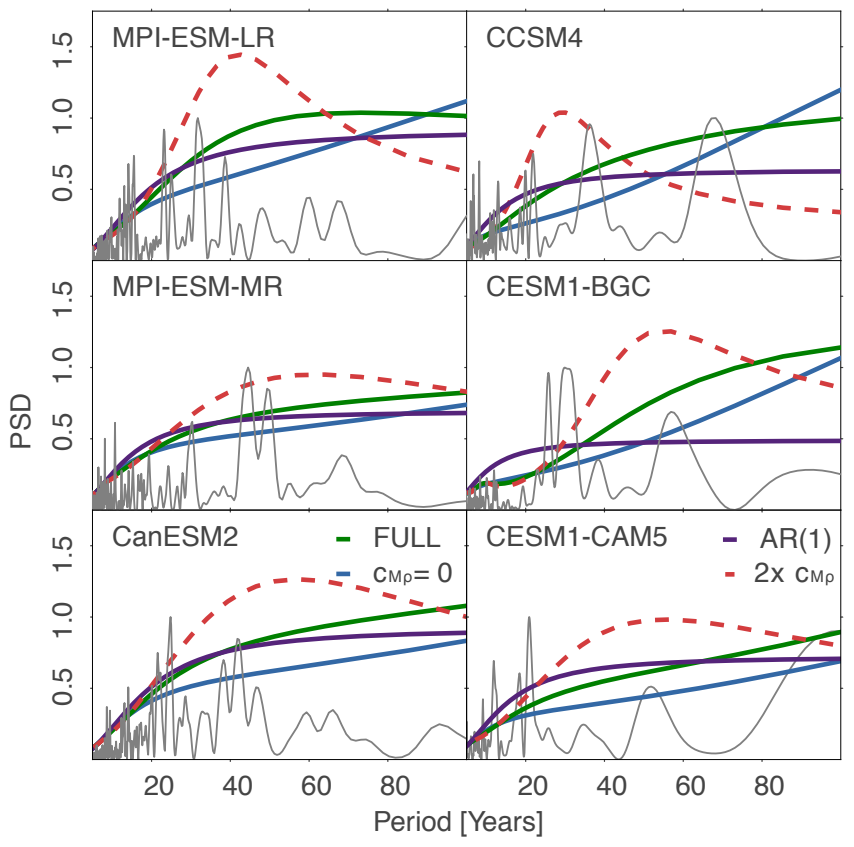

Fig. 10. Analytically derived power spectral densities for different model systems regressed on the individual model time series: green: fully coupled AMOC-NADO density system, blue: decoupled system $c_{m \rho}=0$, purple: AR(1) process, dashed red: a doubled AMOC-NADO coupling $\left(2 \times c_{m},\right)$. AMOC spectra derived from the model time series rescaled relative to their maximum amplitude are shown in light grey.

30 and $70 \mathrm{yr}$. The MPI-ESM-LR and the CCSM4 show the weakest density compensation in the ensemble with slightly higher values for the CESM1-BGC (compare Fig. 8), indicating that a coupled NADO density-AMOC mode might contribute to multi-decadal variability in models with limited density compensation of temperature and salinity anomalies. All three models also show pronounced spectral peaks with periods below $30 \mathrm{yr}$ likely as a result of other sources of AMOC variability. One possible mechanism is variable Labrador Sea convection that has been found to dominate the $20 \mathrm{yr}$ AMOC mode for the CCSM4 model (Danabasoglu et al., 2012). For the MPI-ESM-MR, the CanESM2 and the CESM1-CAM5, our conceptual model only shows slightly enhanced variability in comparison with a simple AR(1) process, suggesting minor importance of the process. For illustration purposes, we also depict spectra with enhanced AMOC-NADO density coupling $\left(2 \times c_{M \rho}\right.$ in red, dashed) that show enhanced multi-decadal variability for all models.

As discussed above, a variety of other processes related to horizontal temperature (Te Raa and Dijkstra, 2002), salinity advection (Jungclaus et al., 2005) and atmospheric variability (Eden and Willebrand, 2001) are found to be relevant for multi-decadal AMOC variability and are not included in this simple conceptual system. However, we find substantial changes in the NADO heat content as a result 
of multi-decadal AMOC variability, which are only partly density-compensated in most models. Based on these results, we propose a conceptual model relating NADO density changes and the AMOC and find the coupled system to enhance multi-decadal variability in three models in the ensemble.

\section{Discussion and conclusions}

By resolving the latitudinal contributions to GMT variance in unperturbed simulations of seven CMIP5 models, we find $33 \%$ of the variance to originate north of $45^{\circ} \mathrm{N}$ in the ensemble mean, which exceeds the share expected by the surface area. Using a time-series graph analysis approach as in Sect. 3.1 (Runge et al., 2012b, 2014), we identify statistically robust couplings between global mean temperature (GMT), Northern Hemisphere sea-ice extent (SIE) and the Atlantic meridional overturning circulation (AMOC) at zero lag and find AMOC and SIE to explain about $21 \%$ of GMT variance in the model ensemble mean. Applying commonality analysis in Sect. 3.2, we disentangle AMOC and SIE contributions and report the contribution that can solely be attributed to the AMOC (SIE) alone to be about $3 \%(14 \%)$ in the ensemble mean. Additionally, we find AMOC and SIE coupling to explain $5 \%$ of the GMT variance suggesting that coupled AMOC-SIE feedbacks might play an important role for North Atlantic climate variability.

Brönnimann (2009) discusses the influence of natural variability during the early 20th century warming and highlights the importance of Arctic warming for this global phenomenon. While anthropogenic aerosol emissions affecting patterns of atmospheric variability are discussed as a possible driver of this anomaly (Booth et al., 2012), our results suggest that also natural multi-decadal AMOC variability could have played an important role (Zhang et al., 2013). The Arctic temperature anomaly coincides with a positive AMO index (Parker et al., 2007) and a sea-ice retreat in the North Atlantic (Macias Fauria et al., 2009; Bengtsson et al., 2004; Semenov and Latif, 2012) that match well with the AMOCsea-ice coupling identified. The drastic reduction of Northern Hemisphere SIE as a result of anthropogenic global warming (Stroeve et al., 2011, 2012; Notz and Marotzke, 2012) will likely lead to decreased contribution of the high northern latitudes to GMT variability, since SIE is found to be a dominant contributor to GMT variance in an unperturbed climate. Additionally, AMOC-SIE feedbacks might weaken in warmer future climates, and consequently also the impact of multidecadal AMOC variability on GMT might be reduced.

In addition to the AMOC influence on surface temperature variability, we find North Atlantic deep-ocean (NADO) heat content to be highly correlated with the AMOC on decadal timescales. Using observational data, Mauritzen et al. (2012) also report a decadal time lag between upper ocean (which is highly correlated with the AMOC at lags between zero and
$3 \mathrm{yr}$ in our model ensemble, not shown) and deep-ocean heat content in the northern North Atlantic.

Meehl et al. (2011) investigated deep-ocean heat uptake anomalies during decades exhibiting a hiatus in the GMT over the 21 st century in global warming model simulations and found a difference of about $1.3 \times 10^{22} \mathrm{~J}$ for the global deep-ocean heat uptake rate per decade below $750 \mathrm{~m}$ and $0.2 \times 10^{22} \mathrm{~J}$ for the Atlantic Basin compared to reference decades. We find anomalous NADO heat uptake with a maximum uptake trend of $0.7 \times 10^{22} \mathrm{~J}$ decade ${ }^{-1}$ averaged over the model ensemble with a range from $1.1 \times 10^{22} \mathrm{~J} \mathrm{decade}^{-1}$ for the MPI-ESM-LR and $0.5 \times 10^{22} \mathrm{~J} \mathrm{decade}^{-1}$ for the CCSM4, CNRM-CM5 and the CESM1-BGC. Our results indicate that North Atlantic deep-ocean heat uptake anomalies connected to a hiatus decade in GMT increase as identified by Meehl et al. (2011) are very well within the range of natural variability of our model ensemble.

As a consequence of an AMOC strengthening related to a positives AMO signal in the late 1990s (Parker et al., 2007), our analysis would suggest NADO heat content to rise for more than a decade after a peak in circulation strength, which is in good agreement with observations from the North Atlantic (Mauritzen et al., 2012). Studies by Guemas et al. (2013) and Balmaseda et al. (2013) demonstrate that ocean heat uptake plays a crucial role in understanding the GMT hiatus over the last decade. Although they find the dominant signal in the upper Pacific Ocean likely related to El NiñoSouthern Oscillation variability, also the North Atlantic deep ocean contributed substantially to anomalous global ocean heat uptake over the last decade (compare Balmaseda et al., 2013, their Fig. S06).

While most of the NADO temperature signal is densitycompensated through changes in salinity, we find a substantial model spread regarding the strength of this compensation. We use time-series graph analysis to extract causal relations out of the highly auto-correlated time series for AMOC and NADO density and found a robust positive link at zero time lag and a negative link between AMOC and NADO density with time lags between 5 and $11 \mathrm{yr}$ (AMOC leads). Based on these results, we propose a stochastic bivariate model that we fit to the time series and find it to explain about $95 \%$ of the density and about $45 \%$ of the AMOC variance in the ensemble average. The AMOC-NADO density feedbacks identified may lead to multi-decadal AMOC variability in models with weak density compensation. Thus, they represent a possible advective mechanism for multi-decadal AMOC variability (Latif, 1998; Te Raa and Dijkstra, 2002; Menary et al., 2011).

Acknowledgements. The work was supported by the Federal Ministry for the Environment, Nature Conservation and Nuclear Safety (11 II 093 Global A SIDS and LDCs). Carl-Friedrich Schleussner was funded by the Deutsche Bundesstiftung Umwelt. Jakob Runge appreciates support by the German National Academic Foundation and the DFG grant no. KU34-1. On 
http://tocsy.pik-potsdam.de/tigramite.php we provide a program with a graphical user interface to estimate the time-series graph. We acknowledge the World Climate Research Programme's Working Group on Coupled Modelling, which is responsible for CMIP, and we thank the climate modeling groups (listed in Table 1 of this paper) for producing and making available their model output. For CMIP the US Department of Energy's Program for Climate Model Diagnosis and Intercomparison provides coordinating support and led development of software infrastructure in partnership with the Global Organization for Earth System Science Portals.

Edited by: V. Lucarini

\section{References}

Ba, J., Keenlyside, N. S., Park, W., Latif, M., Hawkins, E., and Ding, H.: A mechanism for Atlantic multidecadal variability in the Kiel Climate Model, Clim. Dynam., 41, 2133-2144, doi:10.1007/s00382-012-1633-4, 2013.

Balmaseda, M. A., Trenberth, K. E., and Källén, E.: Distinctive climate signals in reanalysis of global ocean heat content, Geophys. Res. Lett., 40, 1754-1759, doi:10.1002/grl.50382, 2013.

Bengtsson, L., Semenov, V. A., and Johannessen, O. M.: The early twentieth-century warming in the Arctic - a possible mechanism, J. Climate, 17, 4045-4057, 2004.

Bentsen, M., Drange, H., Furevik, T., and Zhou, T.: Simulated variability of the Atlantic meridional overturning circulation, Clim. Dynam., 22, 701-720, doi:10.1007/s00382-004-0397-x, 2004.

Booth, B. B. B., Dunstone, N. J., Halloran, P. R., Andrews, T., and Bellouin, N.: Aerosols implicated as a prime driver of twentiethcentury North Atlantic climate variability., Nature, 484, 228-32, doi:10.1038/nature10946, 2012.

Born, A., Stocker, T. F., Raible, C. C., and Levermann, A.: Is the Atlantic subpolar gyre bistable in comprehensive coupled climate models?, Clim. Dynam., 40, 2993-3007, doi:10.1007/s00382012-1525-7, 2012.

Brockwell, P. J. and Davis, R. A.: Time series: theory and methods, Springer, New York, 2009.

Brönnimann, S.: Early twentieth-century warming, Nat. Geosci., 2, 735-736, doi:10.1038/ngeo670, 2009.

Cimatoribus, A. A., Drijfhout, S. S., and Dijkstra, H. A.: Meridional overturning circulation: stability and ocean feedbacks in a box model, Clim. Dynam., doi:10.1007/s00382-012-1576-9, online first, 2012.

Curry, R., McCartney, M., and Joyce, T.: Oceanic transport of subpolar climate signals to mid-depth subtropical waters, Nature, 391, 575-577, 1998.

Danabasoglu, G., Yeager, S. G., Kwon, Y.-O., Tribbia, J. J., Phillips, A. S., and Hurrell, J. W.: Variability of the Atlantic meridional overturning circulation in CCSM4, J. Climate, 25, 5153-5172, doi:10.1175/JCLI-D-11-00463.1, 2012.

Delworth, T. L. and Zeng, F.: Multicentennial variability of the Atlantic meridional overturning circulation and its climatic influence in a 4000 year simulation of the GFDL CM2.1 climate model, Geophys. Res. Lett., 39, 1-6, doi:10.1029/2012GL052107, 2012.
Delworth, T., Zhang, R., and Mann, M.: Decadal to centennial variability of the Atlantic from observations and models, ocean circulation: mechanisms and impacts, Geophys. Monogr. Ser., 173, 131-148, 2007.

Dijkstra, H. A.: Scaling of the Atlantic meridional overturning circulation in a global ocean model, Tellus A, 60, 749-760, 2008.

Dijkstra, H. A., Raa, L., Schmeits, M., and Gerrits, J.: On the physics of the Atlantic multidecadal oscillation, Ocean Dynam., 56, 36-50, doi:10.1007/s10236-005-0043-0, 2006.

Dima, M. and Lohmann, G.: Evidence for two distinct modes of large-scale ocean circulation changes over the last century, J. Climate, 23, 5-16, doi:10.1175/2009JCLI2867.1, 2010.

Ebert-Uphoff, I. and Deng, Y.: Causal discovery for climate research using graphical models, J. Climate, 25, 5648-5665, doi:10.1175/JCLI-D-11-00387.1, 2012.

Eby, M., Weaver, A. J., Alexander, K., Zickfeld, K., Abe-Ouchi, A., Cimatoribus, A. A., Crespin, E., Drijfhout, S. S., Edwards, N. R., Eliseev, A. V., Feulner, G., Fichefet, T., Forest, C. E., Goosse, H., Holden, P. B., Joos, F., Kawamiya, M., Kicklighter, D., Kienert, H., Matsumoto, K., Mokhov, I. I., Monier, E., Olsen, S. M., Pedersen, J. O. P., Perrette, M., Philippon-Berthier, G., Ridgwell, A., Schlosser, A., Schneider von Deimling, T., Shaffer, G., Smith, R. S., Spahni, R., Sokolov, A. P., Steinacher, M., Tachiiri, K., Tokos, K., Yoshimori, M., Zeng, N., and Zhao, F.: Historical and idealized climate model experiments: an intercomparison of Earth system models of intermediate complexity, Clim. Past, 9, 11111140, doi:10.5194/cp-9-1111-2013, 2013.

Eden, C. and Willebrand, J.: Mechanism of interannual to decadal variability of the North Atlantic circulation, J. Climate, 14, 22662280, 2001.

Fernández-Donado, L., González-Rouco, J. F., Raible, C. C., Ammann, C. M., Barriopedro, D., García-Bustamante, E., Jungclaus, J. H., Lorenz, S. J., Luterbacher, J., Phipps, S. J., Servonnat, J., Swingedouw, D., Tett, S. F. B., Wagner, S., Yiou, P., and Zorita, E.: Large-scale temperature response to external forcing in simulations and reconstructions of the last millennium, Clim. Past, 9, 393-421, doi:10.5194/cp-9-393-2013, 2013.

Feulner, G., Rahmstorf, S., Levermann, A., and Volkwardt, S.: On the origin of the surface air temperature difference between the hemispheres in earth's present-day climate, J. Climate, 26, 71367150 doi:10.1175/JCLI-D-12-00636.1, 2013.

Fidel, J., González-Rouco, L., Gonzalez-Rouco, J. F., FernándezDonado, L., Raible, C. C., Barriopedro, D., Lutherbacher, J., Jungclaus, J. H., Swingedow, D. Servonnat, J. Zorita, E. Wagner, S., and Ammann, C. M.: Medieval climate anomaly to Little Ice Age transition as simulated by current climate models, Pages News, 19, 3-4, 2011.

Frankcombe, L. M., Dijkstra, H. A., and von der Heydt, A.: Noise-induced multidecadal variability in the North Atlantic: excitation of normal modes, J. Phys. Oceanogr., 39, 220-233, doi:10.1175/2008JPO3951.1, 2009.

Fürst, J. J., and Levermann, A.: A minimal model for wind- and mixing-driven overturning: threshold behavior for both driving mechanisms, Clim. Dynam., 38, 239-260, doi:10.1007/s00382011-1003-7, 2012.

Gnanadesikan, A.: A simple predictive model for the structure of the oceanic pycnocline, Science, 283, 2077-2079, 1999. 
Gregory, J. M. and Tailleux, R.: Kinetic energy analysis of the response of the Atlantic meridional overturning circulation to $\mathrm{CO}_{2}$-forced climate change, Clim. Dynam., 37, 893-914, doi:10.1007/s00382-010-0847-6, 2011.

Griesel, A. and Maqueda, M. A. M.: The relation of meridional pressure gradients to North Atlantic deep water volume transport in an ocean general circulation model, Clim. Dynam., 26, 781-799, doi:10.1007/s00382-006-0122-z, 2006.

Griffies, S. and Tziperman, E.: A linear thermohaline oscillator driven by stochastic atmospheric forcing, J. Climate, 8, 24402453, 1995.

Guemas, V., Doblas-Reyes, F. J., Andreu-Burillo, I., and Asif, M.: Retrospective prediction of the global warming slowdown in the past decade, Nat. Clim. Change, 3, 649-653, doi:10.1038/nclimate1863, 2013.

Hofer, D., Raible, C. C., and Stocker, T. F.: Variations of the Atlantic meridional overturning circulation in control and transient simulations of the last millennium, Clim. Past, 7, 133-150, doi:10.5194/cp-7-133-2011, 2011.

Holland, M. M. and Bitz, C. M.: Polar amplification of climate change in coupled models, Clim. Dynam., 21, 221-232, doi:10.1007/s00382-003-0332-6, 2003.

Huisman, S. E., den Toom, M., Dijkstra, H. A., and Drijfhout, S.: An indicator of the multiple equilibria regime of the Atlantic meridional overturning circulation, J. Phys. Oceanogr., 40, 551-567, doi:10.1175/2009JPO4215.1, 2010.

Hurrell, J. and Deser, C.: North Atlantic climate variability: the role of the North Atlantic Oscillation, J. Marine Syst., 78, 28-41, doi:10.1016/j.jmarsys.2008.11.026, 2009.

Johnson, H. L., Marshall, D. P., and Sproson, D. A. J.: Reconciling theories of a mechanically driven meridional overturning circulation with thermohaline forcing and multiple equilibria, Clim. Dynam., 29, 821-836, doi:10.1007/s00382-007-0262-9, 2007.

Jones, G. S., Stott, P. A., and Christidis, N.: Attribution of observed historical near-surface temperature variations to anthropogenic and natural causes using CMIP5 simulations, J. Geophys. Res.Atmos., 118, 4001-4024, doi:10.1002/jgrd.50239, 2013.

Jungclaus, J., Haak, H., Latif, M., and Mikolajewicz, U.: ArcticNorth Atlantic interactions and multidecadal variability of the meridional overturning circulation, J. Climate, 18, 4013-4031, 2005

Knight, J. R., Allen, R. J., Folland, C. K., Vellinga, M., and Mann, M. E.: A signature of persistent natural thermohaline circulation cycles in observed climate, Geophys. Res. Lett., 32, L20708, doi:10.1029/2005GL024233, 2005.

Knight, J. R., Folland, C. K., and Scaife, A. A.: Climate impacts of the Atlantic multidecadal oscillation, Geophys. Res. Lett., 33, L17706, doi:10.1029/2006GL026242, 2006.

Knudsen, M. F., Seidenkrantz, M.-S., Jacobsen, B. H., and Kuijpers, A.: Tracking the Atlantic Multidecadal Oscillation through the last 8,000 years, Nat. Comm., 2, 178, doi:10.1038/ncomms1186, 2011.

Latif, M.: Dynamics of interdecadal variability in coupled ocean atmosphere models, J. Climate, 11, 602-624, 1998.

Lee, S. and Wang, C.: Delayed advective oscillation of the Atlantic thermohaline circulation, J. Climate, 23, 1254, doi:10.1175/2009JCLI3339.1, 2010.
Levermann, A. and Born, A.: Bistability of the subpolar gyre in a coarse resolution climate model, Geophys. Res. Lett., 34, L24605, doi:10.1029/2007GL031732, 2007.

Levermann, A., Mignot, J., Nawrath, S., and Rahmstorf, S.: The role of Northern Sea ice cover for the weakening of the thermohaline circulation under global warming, J. Climate, 20, 41604171, doi:10.1175/JCLI4232.1, 2007.

Levitus, S., Antonov, J., Boyer, T., and Stephens, C.: Warming of the world ocean, Science, 287, 2225-2229, doi:10.1126/science.287.5461.2225, 2000.

Macias Fauria, M., Grinsted, A., Helama, S., Moore, J., Timonen, M., Martma, T., Isaksson, E., and Eronen, M.: Unprecedented low twentieth century winter sea ice extent in the Western Nordic Seas since A. D. 1200, Clim. Dynam., 34, 781-795, doi:10.1007/s00382-009-0610-z, 2009.

Manabe, S. and Stouffer, R. J.: Two stable equilibria of a coupled ocean-atmosphere model, J. Climate, 1, 841-866, 1988.

Mantua, N. J., Hare, S. R., Zhang, Y., Wallace, J. M., and Francis, R. C.: A Pacific interdecadal climate oscillation with impacts on salmon production, B. Am. Meteorol. Soc., 78, 1069-1079, 1997.

Marotzke, J.: Boundary mixing and the dynamics of threedimensional thermohaline circulations, J. Phys. Oceanogr., 27, 1713-1728, 1997.

Marzeion, B. and Drange, H.: Diapycnal mixing in a conceptual model of the Atlantic meridional overturning circulation, DeepSea Res. Pt. II, 53, 226-238, 2006.

Mauritzen, C., Melsom, A., and Sutton, R. T.: Importance of density-compensated temperature change for deep North Atlantic Ocean heat uptake, Nat. Geosci.,5, 905-910, doi:10.1038/ngeo1639, 2012.

Medhaug, I., Langehaug, H. R., Eldevik, T., Furevik, T., and Bentsen, M.: Mechanisms for decadal scale variability in a simulated Atlantic meridional overturning circulation, Clim. Dynam. 39, 77-93, doi:10.1007/s00382-011-1124-z, 2011.

Meehl, G. A., Arblaster, J. M., Fasullo, J. T., Hu, A., and Trenberth, K. E.: Model-based evidence of deep-ocean heat uptake during surface-temperature hiatus periods, Nat. Clim. Change, 1 , 360-364, doi:10.1038/nclimate1229, 2011.

Menary, M. B., Park, W., Lohmann, K., Vellinga, M., Palmer, M. D., Latif, M., and Jungclaus, J. H.: A multimodel comparison of centennial Atlantic meridional overturning circulation variability, Clim. Dynam., 38, 2377-2388, doi:10.1007/s00382-011-1172-4, 2011.

Mengel, M., Levermann, A., Schleussner, C.-F., and Born, A.: Enhanced Atlantic subpolar gyre variability through baroclinic threshold in a coarse resolution model, Earth Syst. Dynam., 3, 189-197, doi:10.5194/esd-3-189-2012, 2012.

Mohino, E., Janicot, S., and Bader, J.: Sahel rainfall and decadal to multi-decadal sea surface temperature variability, Clim. Dynam., 37, 419-440, doi:10.1007/s00382-010-0867-2, 2010.

Notz, D. and Marotzke, J.: Observations reveal external driver for Arctic sea-ice retreat, Geophys. Res. Lett., 39, L08502, doi:10.1029/2012GL051094, 2012.

Ortega, P., Montoya, M., González-Rouco, F., Mignot, J., and Legutke, S.: Variability of the Atlantic meridional overturning circulation in the last millennium and two IPCC scenarios, Clim. Dynam., 38, 1925-1947, doi:10.1007/s00382-011-1081-6, 2011. 
Otterå, O., Bentsen, M., Drange, H., and Suo, L.: External forcing as a metronome for Atlantic multidecadal variability, Nat. Geosci., 3, 688-694, doi:10.1038/ngeo955, 2010.

Park, W. and Latif, M.: Multidecadal and multicentennial variability of the meridional overturning circulation, Geophys. Res. Lett., 35, L22703, doi:10.1029/2008GL035779, 2008.

Park, W. and Latif, M.: Atlantic Meridional Overturning Circulation response to idealized external forcing, Clim. Dynam., 39, 17091726, doi:10.1007/s00382-011-1212-0, 2011.

Parker, D., Folland, C., Scaife, A., Knight, J., Colman, A., Baines, P., and Dong, B.: Decadal to multidecadal variability and the climate change background, J. Geophys. Res., 112, 118, doi:10.1029/2007JD008411, 2007.

Persechino, A., Marsh, R., Sinha, B., Megann, A. P., Blaker, A. T., and New, A. L.: Decadal-timescale changes of the Atlantic overturning circulation and climate in a coupled climate model with a hybrid-coordinate ocean component, Clim. Dynam., 39, 10211042, doi:10.1007/s00382-012-1432-y, 2012.

Rahmstorf, S.: On the freshwater forcing and transport of the Atlantic thermohaline circulation, Clim. Dynam., 12, 799-811, 1996.

Runge, J., Heitzig, J., Marwan, N., and Kurths, J.: Quantifying causal coupling strength: a lag-specific measure for multivariate time series related to transfer entropy, Phys. Rev. E, 86, 061121, doi:10.1103/PhysRevE.86.061121, 2012a.

Runge, J., Heitzig, J., Petoukhov, V., and Kurths, J.: Escaping the curse of dimensionality in estimating multivariate transfer entropy, Phys. Rev. Lett., 108, 1-5, doi:10.1103/PhysRevLett.108.258701, 2012b.

Runge, J., Petoukhov, V., and Kurths, J.: "Quantifying the strength and delay of climatic interactions: the ambiguities of cross correlation and a novel measure based on graphical models", J. Climate, 27, 720-739, 2014.

Saenko, O.: Energetics of weakening and recovery of the Atlantic overturning in a climate change simulation, Geophys. Res. Lett., 40, 888-892, doi:10.1002/grl.50101, 2013.

Schewe, J. and Levermann, A.: The role of meridional density differences for a wind-driven overturning circulation, Clim. Dynam., 34, 547-556, doi:10.1007/s00382-009-0572-1, 2009.

Schlesinger, M. and Ramankutty, N.: An oscillation in the global climate system of period 65-70 years, Nature, 367, 723-726, doi:10.1038/367723a0, 1994.

Screen, J. A. and Simmonds, I.: The central role of diminishing sea ice in recent Arctic temperature amplification, Nature, 464, 1334-1337, doi:10.1038/nature09051, 2010.

Seibold, D. and McPhee, R.: Commonality analysis: a method for decomposing explained variance in multiple regression analyses, Human Comm. Res., 5, 355-365, 1979.

Semenov, V. A. and Latif, M.: The early twentieth century warming and winter Arctic sea ice, The Cryosphere, 6, 1231-1237, doi:10.5194/tc-6-1231-2012, 2012.

Sévellec, F., and Fedorov, A. V.: The leading, interdecadal eigenmode of the Atlantic meridional overturning circulation in a realistic ocean model, J. Climate, 26, 2160-2183, doi:10.1175/JCLID-11-00023.1, 2013.

Sijp, W. P., Gregory, J. M., Tailleux, R., and Spence, P.: The key role of the western boundary in linking the AMOC strength to the north-south pressure gradient, J. Phys. Oceanogr., 42, 628643, doi:10.1175/JPO-D-11-0113.1, 2012.
Stommel, H.: Thermohaline convection with two stable regimes of flow, Tellus, 13, 224-230, 1961.

Stroeve, J. C., Serreze, M. C., Holland, M. M., Kay, J. E., Malanik, J., and Barrett, A. P.: The Arctic's rapidly shrinking sea ice cover: a research synthesis, Clim. Change, 110, 1005-1027, doi:10.1007/s10584-011-0101-1, 2011.

Stroeve, J. C., Kattsov, V., Barrett, A., Serreze, M., Pavlova, T., Holland, M., and Meier, W. N.: Trends in Arctic sea ice extent from CMIP5, CMIP3 and observations, Geophys. Res. Lett., 39, L16502, doi:10.1029/2012GL052676, 2012.

Taylor, K. E., Stouffer, R. J., and Meehl, G. A.: An overview of CMIP5 and the experiment design, B. Am. Meteorol. Soc., 93, 485-498, 2012.

Te Raa, L. A. and Dijkstra, H. A.: Instability of the thermohaline ocean circulation on interdecadal timescales, J. Phys. Oceanogr., 32, 138-160, 2002.

Thorpe, R., Gregory, J., and Johns, T.: Mechanisms determining the Atlantic thermohaline circulation response to greenhouse gas forcing in a non-flux-adjusted coupled climate model, J. Climate, 14, 3102-3116, 2001.

Timmermann, A. and Latif, M.: Northern hemispheric interdecadal variability: a coupled air-sea mode, J. Climate, 11, 1906-1931, 1998.

Tulloch, R. and Marshall, J.: Exploring mechanisms of variability and predictability of Atlantic meridional overturning circulation in two coupled climate models, J. Climate, 25, 4067-4080, doi:10.1175/JCLI-D-11-00460.1, 2012.

Vimont, D. J. and Kossin, J. P.: The Atlantic Meridional Mode and hurricane activity, Geophys. Res. Lett., 34, L07709, doi:10.1029/2007GL029683, 2007.

Wouters, B., Drijfhout, S., and Hazeleger, W.: Interdecadal NorthAtlantic meridional overturning circulation variability in ECEARTH, Clim. Dynam., 39, 2695-2712, doi:10.1007/s00382012-1366-4, 2012.

Yashayaev, I.: Hydrographic changes in the Labrador Sea, 1960-2005, Prog. Oceanogr., 73, 242-276, doi:10.1016/j.pocean.2007.04.015, 2007.

Yashayaev, I., van Aken, H. M., Holliday, N. P., and Bersch, M.: Transformation of the Labrador sea water in the subpolar North Atlantic, Geophys. Res. Lett., 34, L22605, doi:10.1029/2007GL031812, 2007.

Zanchettin, D., Rubino, A., and Jungclaus, J. H.: Intermittent multidecadal-to-centennial fluctuations dominate global temperature evolution over the last millennium, Geophys. Res. Lett., 37, L14702, doi:10.1029/2010GL043717, 2010.

Zhang, R. and Delworth, T. L.: A new method for attributing climate variations over the Atlantic Hurricane Basin's main development region, Geophys. Res. Lett., 36, L06701, doi:10.1029/2009GL037260, 2009.

Zhang, R., Delworth, T., and Held, I.: Can the Atlantic Ocean drive the observed multidecadal variability in Northern Hemisphere mean temperature?, Geophys. Res. Lett., 34, L02709, doi:10.1029/2006GL028683, 2007.

Zhang, R., Delworth, T. L., Sutton, R., Hodson, D. L., Dixon, K. W., Held, I. M., Kushnir, Y., Marshall, J., Ming, Y., and Msadek, R.: Have aerosols caused the observed Atlantic multidecadal variability?, J. Atmos. Sci., 70, 1135-1144, doi:10.1175/JAS-D-120331.1, 2013. 